\title{
THE PHYSICAL-MECHANICAL AND ELECTRICAL PROPERTIES OF CAST ALUMINUM-BASED ALLOYS REINFORCED WITH DIAMOND NANOPARTICLES
}

\author{
S. A. Vorozhtsov, ${ }^{1,2}$ A. P. Khrustalyov, ${ }^{1,2}$ D. G. Eskin, ${ }^{1,3}$ \\ S. N. Kulkov, ${ }^{1,2}$ and N. Alba-Baena ${ }^{4}$
}

The results obtained from investigations into the microstructure and physical-mechanical and electrical properties of cast aluminum-based alloys reinforced with nanodiamonds are presented. Addition of the diamond nanoparticles is shown to change the structural parameters and improve the mechanical properties of the materials.

Keywords: aluminum, casting, ultrasonic treatment, nanodiamonds, mechanical properties.

\section{INTRODUCTION}

Nowadays aluminum-based alloys reinforced with non-metallic particles have attracted considerable interest of experts engaged in different fields of engineering and technology. This is due to high specific strength, hardness, wear resistance, and other characteristics of the materials. A versatile method for producing composites such as these is casting. Different matrices are used for this purpose, including a commercial A356 aluminum alloy of the Al-Si system (the Russian analog is an AK7 alloy). Owing to good castability, weldability, corrosion resistance, and fairly high mechanical properties, cast A356 alloys have widespread applications in automotive, airospace and other industries [1]. Micro-or nanoparticles of oxides, carbides, borides, etc., can be used as reinforcing species. Of great importance is the introduction of high-elastic-modulus detonation diamond nanoparticles into a soft aluminum matrix [2-4]. The elastic modulus of nanodiamonds is $880 \mathrm{GPa}$ and the hardness is $70 \mathrm{GPa}$. Unlike oxides, carbides, and borides which, as a rule, enter into interaction with the matrix and change their structure, diamond nanoparticles exhibit stability at high temperatures (up to $1000^{\circ} \mathrm{C}$ [5]) and may stabilize the mechanical and physical properties of the alloys in a wide temperature range.

Direct addition of high-melting-point particles (specifically those of nanometer size) into the melt is hardly possible because of their tendency to agglomeration and floatation by virtue of poor wetting by liquid metals. The problem can be solved using an exposure of the metal melt to external fields, which causes deagglomeration of the particles and their dispersion over the melt volume and then over the ingot structure. A most efficient melt processing technique is ultrasonic treatment. The latter produces alloy grain refinement and gives rise to dispersion of the reinforcing nanoparticles over the structure of the material [6-8]. What is more, ultrasonic treatment enhances degassing of the melt and further mixing of the nanoparticles and inhibits dendritic liquation and concentration of nonmetallic inclusions at grain boundaries, which has a positive effect on the formation of uniform metal structure during crystallization [9]. Our purpose here is to investigate the physical-mechanical and electrical properties of A356 aluminum alloys reinforced with detonation diamond nanoparticles.

${ }^{1}$ National Research Tomsk State University, Tomsk, Russia; ${ }^{2}$ Institute of Strength Physics and Materials Science of the Siberian Branch of the Russian Academy of Sciences, Tomsk, Russia; ${ }^{3}$ Brunel Centre for Advanced Solidification Technology, Brunel University; ${ }^{4}$ Universidad Autonoma De Ciudad Juares, Chihuanua, Mexico, e-mail: vorn1985@gmail.com. Translated from Izvestiya Vysshikh Uchebnykh Zavedenii, Fizika, No. 11, pp. 31-36, November, 2014. Original article submitted May 21, 2014; revision submitted September 4, 2014. 


\section{TEST MATERIALS AND INVESTIGATION TECHNIQUES}

The test materials were a commercial A356 aluminum alloy of the Al-Si system and a batch mixture of carbon in a crystalline and an amorphous phases, and detonation nanodiamonds [2, 5, 10]. The alloy was melted in a graphite crucible holding $1 \mathrm{~kg}$ of the melt. Ultrasonic degassing of the melt was performed at a melt temperature of $720^{\circ} \mathrm{C}$ for 1 min. followed by addition of nanoparticles subjected to concurrent ultrasonic treatment by means of a water-cooled $5 \mathrm{~kW}$ magnetostrictive transducer operating at a frequency of $17.5 \mathrm{kHz}$. The amplitude of the conical niobium radiator was $\sim 30 \mu \mathrm{m}$. To improve the wettability of the detonation diamond nanoparticles, they were premixed with an ultrafinegrained aluminum powder, and an aluminum foil was wrapped around the resultant mixture. A rod-shaped container with the powder was warmed up in a furnace at a temperature of $200^{\circ} \mathrm{C}$ and then placed in a cavitation zone in the melt. On addition of the nanoparticles the melt was subjected to ultrasonic treatment for $10 \mathrm{~min}$. and cast in a $\varnothing 30 \times 110 \mathrm{~mm}$ metallic mould at $700^{\circ} \mathrm{C}$. The amount of the nanoparticles in the melt was 0.2 and $1 \mathrm{wt} . \%$. Reference samples were produced using similar processing parameters but without addition of the nanoparticles.

The phase composition and structural parameters of the detonation nanodiamonds and aluminum alloys were investigated by a diffractometer operating in $\mathrm{Cu} K_{\alpha}$ radiation. The coherently diffracting domain (CDD) size and the lattice microdistortions $\left\langle\varepsilon^{2}\right\rangle^{1 / 2}$ were calculated by the Williamson-Hall method, allowing for broadening of all reflections seen on the x-ray diffraction pattern. It is essential that these parameters be determined to identify the reinforcement mechanisms and processes developing in the bulk of the materials as the diamond nanoparticles are added. The morphological structure of the nanopowder was examined under a Philips CM 12 transmission electron microscope. The mechanical behavior of the aluminum alloy samples subjected to quasi-static tension was studied with the use of an Instron 3369 testing machine. The guaranteed testing machine frame stiffness corresponded to a maximum load of $250 \mathrm{kN}$ and the measurement error of the force cell was $0.5 \mathrm{kN}$. On trials the ultimate load was $\leq 1.5 \mathrm{kN}$. The mobile grip velocity was $0.01 \mathrm{~s}^{-1}$, which corresponds to a deformation velocity of $2 \times 10^{-4} \mathrm{~s}^{-1}$. The structure of the resultant materials was examined under a Philips SEM 515 scanning electron microscope and a Neophot 21 optical microscope. The pore space volume and average grain and pore size in the structure of the materials were found by the random secant method [11].

The microhardness and Young's modulus of the materials were measured by a NanoIndenter G200/XP microhardness tester under a load of $250 \mathrm{~g}$ and the hardness was determined by a stationary Brinell hardness tester under a load of $1 \mathrm{~kg}$. Ten hardness measurements were performed in different surface areas of the samples. The measurements of the electrical resistance were performed using a 4-point electric circuit with concurrent heating of the samples to estimate the temperature coefficient of resistance.

\section{RESULTS AND DISCUSSION}

A transmission electron microscope (TEM) image of a powder containing detonation diamond nanoparticles is demonstrated in Fig. 1a. The powder is seen to be of fine crystalline morphological structure, but according to the data obtained from a scanning electron microscope (SEM) examination, it contains agglomerates of $10 \mu \mathrm{m}$ particles. Interpretation of the electron microdiffraction pattern shown in Fig. $1 b$ for the powder under consideration has revealed that the diffraction lines correspond to the cubic diamond phase. The average size of the diamond nanoparticles found from the electron microdiffraction pattern was $4 \mathrm{~nm}$, which agrees with the results obtained by the small-angle $\mathrm{x}$-ray scattering technique [2]. An x-ray phase analysis has indicated that the powder contains an amorphous x-ray phase (40 $\pm 5 \%)$ and a diamond phase $(45 \pm 5 \%)$ as well as traces of the carbon crystalline phase. According to an $x$-ray diffraction analysis, the CDD average size in the nanopowder was $4 \mathrm{~nm}$ and the lattice microdistortion was $1.7 \times 10^{-2}$. Thus, it can be said with confidence that the nanopowder had fine crystalline structure and the particle size was $\leq 10 \mathrm{~nm}$.

The microstructure of an aluminum alloy reinforced with a varying amount of nanoparticles is presented in Fig. 2. The resultant materials are seen to exhibit porosity. The pores in the initial material are small and the volume of the pore space is $<2 \%$. Large pores appear in the alloys reinforced with nanoparticles in addition to the fine nanodiamond fraction, with the total volume of the pore space being increased with increase in the amount of the nanoparticles. It is conceivable that large pores are formed around nanoparticle agglomerates. The calculated 

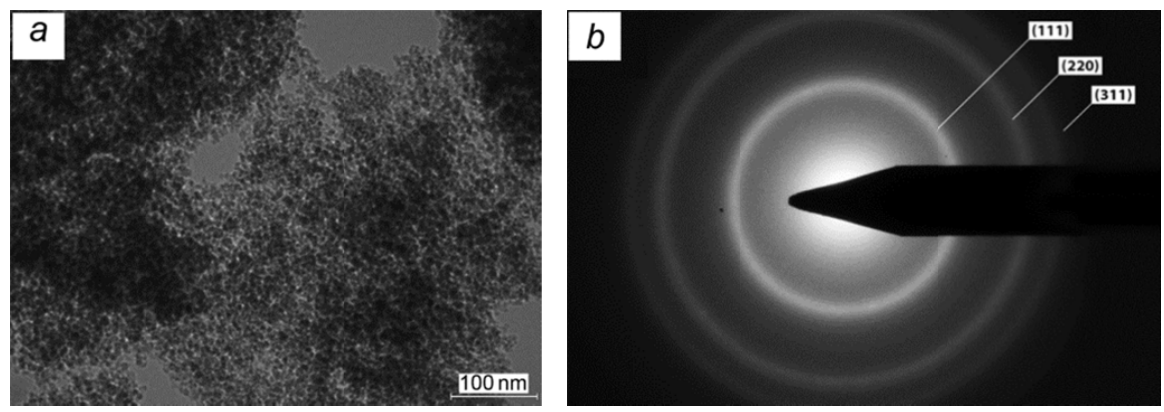

Fig. 1. TEM image of a diamond nanopowder containing detonation diamond nanoparticles $(a)$ and an electron microdiffraction pattern $(b)$.
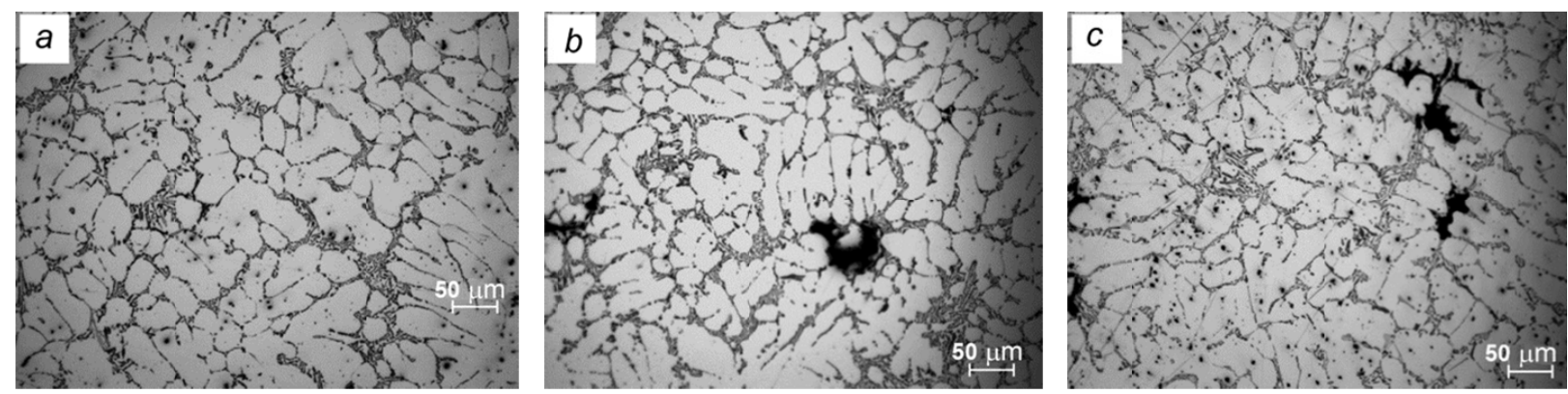

Fig. 2. Microstructure of the initial A356 alloy (a), A356 + 0.2\% C (b), and A356 + 1\% C (c).

average pore size in the initial alloy was found to be $3 \mu \mathrm{m}$, whereas on addition of nanoparticles, it amounted to $28 \mu \mathrm{m}$ in materials containing $0.2 \% \mathrm{C}$ and to $20 \mu \mathrm{m}$ with $1 \% \mathrm{C}$. The calculated average grain size in the alloys with $0.2 \% \mathrm{C}$ was reduced from 210 down to $170 \mu \mathrm{m}$, and on addition of $1 \% \mathrm{C}$, it increased to $220 \mu \mathrm{m}$, i.e. the average grain size was the same as in the initial alloy.

The data obtained from the x-ray diffraction analysis are summarized in Table 1 below. On addition of the reinforcing nanoparticles the CDD size of the aluminum-based phase is seen to reduce. Specifically, the CDD size of aluminum in the initial state with no nanoparticle addition is $140 \mathrm{~nm}$, whereas with addition of $1 \% \mathrm{C}$ to the alloy, it is reduced down to $80 \mathrm{~nm}$. Besides, the lattice microdistortion is also decreased and is nearly halved in the samples reinforced with $1 \% \mathrm{C}$. In all cases under consideration, the aluminum lattice parameter is higher than the tabulated value (4.0494 $\AA$ [12]). The increase in the lattice parameter may be due to a high degree of the microdistortions both by virtue of the elements dissolved in aluminum and on account of the nanoparticle inclusion into the matrix. Notably, in the material with $1 \% \mathrm{C}$, the decrease in the microdistortion occurs with a decrease in the lattice parameter which becomes very nearly equal to the tabulated value.

Stress-strain diagrams for tension test alloy specimens with varying percentage of the carbon nanoparticles are presented in Fig. 3. Introduction of $0.2 \% \mathrm{C}$ into the alloy was found to provide a significant improvement in the mechanical properties of the material: the ultimate strength, yield strength, elastic modulus, and ductility are increased, which agrees well with the lattice microdistortion data given in Table 1. The improvement in the mechanical properties of the alloys with $0.2 \% \mathrm{C}$ is likely to occur by the Orowan mechanism [13]. However, addition of a large amount of the nanoparticles (up to $1 \% \mathrm{C}$ ) to the aluminum alloy gives rise to porosity and nanoparticle agglomeration, causing degradation of the mechanical properties of the alloy and providing lower instability of the plastic flow.

The SEM fracture surface images for aluminum alloys are shown in Fig. 4. The fracture exhibits 100-300 $\mu \mathrm{m}$ shrinkage pores formed on the fracture surface during crystallization (white contour lines). Even though the fracture pattern remains unchanged, the increasing pore volume causes premature failure of the alloys with a high percentage of the reinforcing nanoparticles. 
TABLE 1. The Results of the X-Ray Diffraction Analysis of the Alloys Studied

\begin{tabular}{c|c|c|c} 
Material & CDD size of Al, nm & $\left\langle\varepsilon^{2}\right\rangle^{1 / 2}$ & Lattice parameter $a$ of Al, $\AA$ \\
\hline A356 & 140 & $5 \times 10^{-4}$ & 4.059 \\
\hline A356 + 0.2\% C & 90 & $4.7 \times 10^{-4}$ & 4.0629 \\
\hline A356 + 1\% C & 80 & $2.8 \times 10^{-4}$ & 4.0519 \\
\hline
\end{tabular}

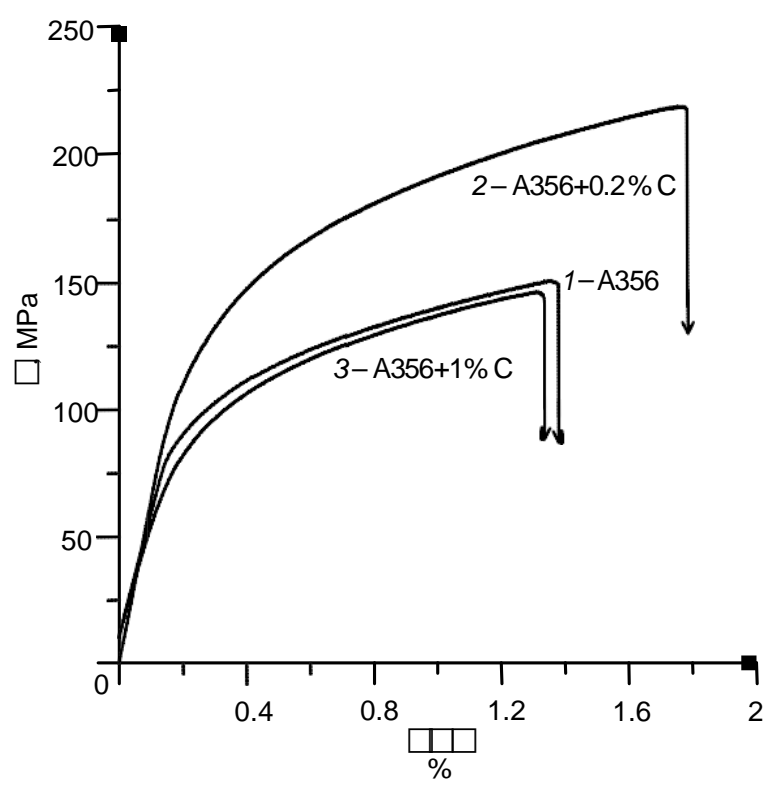

Fig. 3. Tensile stress-strain curves for cast alloys with a varying amount of the reinforcing nanoparticles.
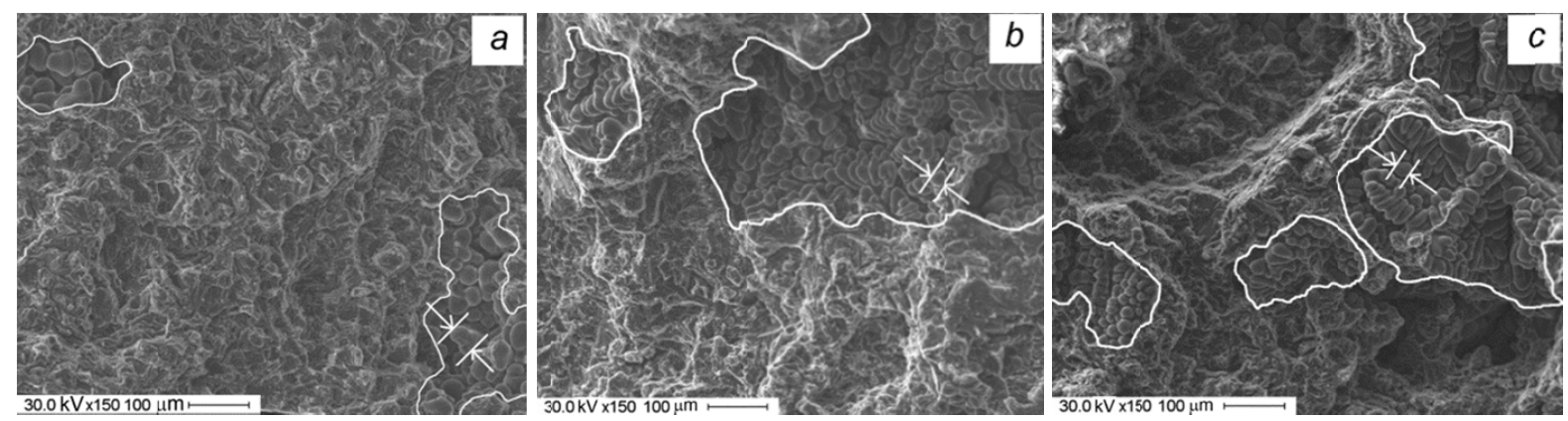

Fig. 4. Fracture surfaces of the initial aluminum alloy $(a)$ and of the aluminum-based alloys: A356 + 0.2\% C (b) and A356 + 1\% C (c).

The mechanical properties of the alloys are listed in Table 2 below. The hardness of the materials measured in the Vickers and Brinell hardness tests is seen to increase. Moreover, there is also an increase in the engineering elastic modulus calculated from the stress-strain curves and Young's modulus determined by means of indentation. The increase in the elastic modulus and strength of the alloys occurs with a reduction in the average size of the dendritic arm spacing from $37 \mu \mathrm{m}$ in the initial alloy down to $27 \mu \mathrm{m}$ in the alloys reinforced with nanoparticles (marked by arrows).

The dependence of variations in the specific electrical resistance $\rho$ and the temperature coefficient of resistance $\alpha_{\rho}$ of the materials on the amount of the diamond nanoparticles in the alloys is presented in Fig. 5. Introduction of 
TABLE 2. The Mechanical Properties of the Cast Alloys Studied

\begin{tabular}{c|c|c|c|c}
\hline Material & Microhardness, MPa & Brinell hardness & $\begin{array}{c}\text { Young’s modulus, GPa } \\
\text { (indentation) }\end{array}$ & $\begin{array}{c}E_{\text {eff, GPa }} \\
\text { (stress-strain curves) }\end{array}$ \\
\hline A356 & $870 \pm 10$ & $40 \pm 5$ & $40 \pm 5$ & $48 \pm 5$ \\
\hline A356 + 0.2\% C & $1380 \pm 10$ & $55 \pm 5$ & $86 \pm 5$ & $65 \pm 5$ \\
\hline A356 + 1\% C & $1360 \pm 10$ & $60 \pm 5$ & $85 \pm 5$ & $44 \pm 5$ \\
\hline
\end{tabular}

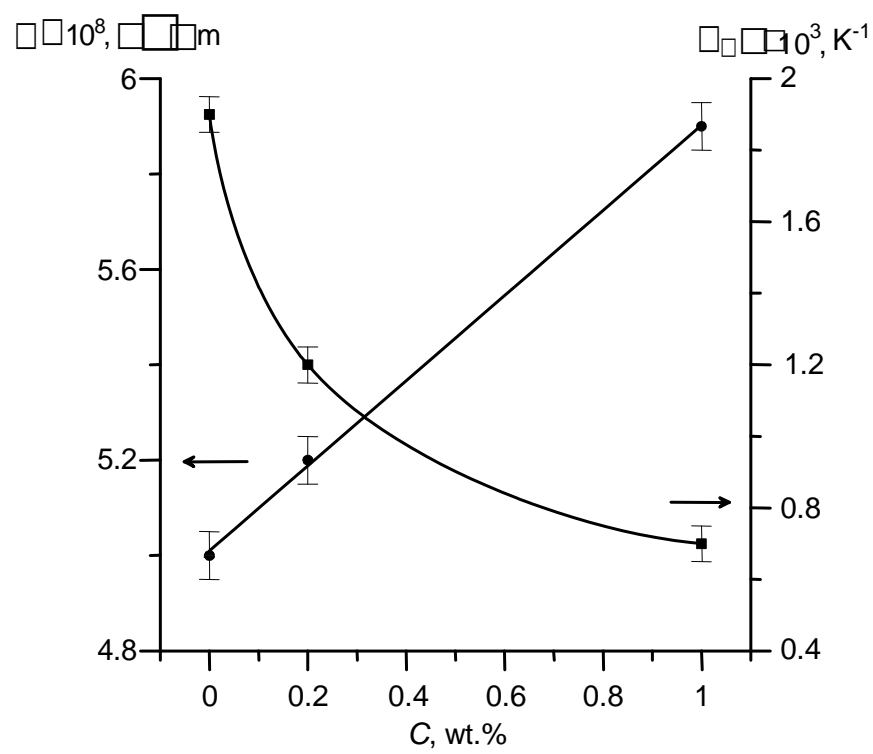

Fig. 5. Dependence of the electrical resistance and temperature coefficient of resistance on the concentration of the carbon nanoparticles.

the nanoparticles into the initial alloy increases the resistance from $5 \times 10^{-8}$ to $5.9 \times 10^{-8} \Omega \mathrm{m}$. The data account for the porosity of the resultant alloys. Besides, the temperature coefficient of electrical resistance is decreased from $1.9 \times 10^{-3}$ to $0.7 \times 10^{-3} \mathrm{~K}^{-1}$. The change in $\rho$ and $\alpha_{\rho}$ is likely to be due to the effect of the concentration of the nanoparticles that form additional grain boundaries. Notably, the nanoparticles may exhibit high resistance because of their low conductivity.

\section{CONCLUSIONS}

We have studied the microstructure and physical-mechanical and electrical properties of a commercial cast A356 alloy reinforced with diamond nanoparticles and arrived at the following conclusions:

1. The size of the coherently diffracting domain of the aluminum phase in the nano-reinforced aluminum alloys is reduced from 140 to $80 \mathrm{~nm}$, which is caused by multifactor changes in the composition and structure of the alloyed compounds and calls for further investigations.

2. Introduction of $0.2 \% \mathrm{C}$ involves a significant improvement in the mechanical properties: the ultimate strength, yield strength, elastic modulus, ductility, and hardness of the materials are increased.

3. Addition of the reinforcing particles to the initial alloy increases the porosity of the resultant material. This means that the process of preparation of the composites should be optimized.

4. Introduction of the carbon nanoparticles into the initial alloy increases the specific resistance and decreases the temperature coefficient of electrical resistance. 
The work was financed by the Ministry of Education and Science of the Russian Federation within the Federal Target Program "Scientific and Scientific-Pedagogical Personnel of Innovative Russia” for 2014-2020 (Agreement № 14.578.21.0025, UID RFME157814X0025) and the Program to Improve the Competitiveness of Tomsk State University among the World Leading Research and Education Centers.

\section{REFERENCES}

1. Q. G. Wang, Metall. Mater. Trans. A, 34A, 2887-2899 (2003).

2. $\quad$ G. V. Sakovich, V. F. Komarov, and E. A. Petrov, Sverkhtverd. Mater., No. 3, 3-18 (2002).

3. S. Vorozhtsov, A. Vorozhtsov, and S. Kulkov, Light Metals, John Grandfield, ed., TMS (the Minerals, Metals and Materials Society) (2014), pp. 1431-1435.

4. $\quad$ S. N. Kulkov and S. A. Vorozhtsov, Russ. Phys. J., 53, No. 11, 1153-157 (2011).

5. A. A. Gromov, S. A. Vorozhtsov, V. F. Komarov, et al., Mater. Lett., 91, 198-201 (2013).

6. G. I. Eskin, Sonochem., 1, 59-63 (1994).

7. H.Choi, M. Jones, H. Konishi, and X. Li, Metall. Mater. Trans. A, 43A, 738-746 (2012).

8. S. Vorozhtsov, D. Eskin, A. Vorozhtsov, and S. Kulkov, Light Metals, John Grandfield, TMS (The Minerals, Metals and Materials Society) (2014), pp. 1373-1377.

9. G. I. Eskin, Ultrasonic Treatment of Light Alloy Melts, Amsterdam, Gordon and Breach OPA (1998).

10. S. A. Vorozhtsov, S. P. Buyakova, and S. N. Kulkov, Russ. J. Non-Ferrous Metals, 53, No. 5, 420-424 (2012).

11. Ya. S. Umanskii, Yu. A. Skakov, A. N. Ivanov, and L. N. Rastorguev, Crystallography, Roentgenography, and Electron Microscopy [in Russian], Moscow, Metallurgiya (1982).

12. Powder Diffraction Standards, ASTM, Card 4-787 Aluminum.

13. E. Orowan, in: Proc. Symp. Intern. Stress in Metals and Alloys, London, Inst. Met., 451-454 (1948). 